\title{
Feasibility of a 6-Month Home-Based Fall Prevention Exercise Program in Older Adults with COPD
}

\author{
Marla K Beauchamp (DD ${ }^{1-3}$ \\ Cindy Ellerton ${ }^{1,3}$ \\ Renata Kirkwood (D) \\ Dina Brooks $\mathbb{D}^{1,3}$ \\ Julie Richardson' \\ Roger S Goldstein $\mathbb{D}^{3,4}$ \\ Stewart Pugsley ${ }^{2,5}$ \\ Diana Hatzoglou ${ }^{2}$ \\ 'School of Rehabilitation Science, \\ McMaster University, Hamilton, ON, \\ Canada; ${ }^{2}$ Firestone Institute for \\ Respiratory Health, St. Joseph's \\ Healthcare, Hamilton, ON, Canada; \\ ${ }^{3}$ Respiratory Rehabilitation, West Park \\ Healthcare Centre, Toronto, ON, \\ Canada; ${ }^{4}$ Department of Medicine, \\ University of Toronto, Toronto, ON, \\ Canada; ${ }^{5}$ Department of Medicine, \\ McMaster University, Hamilton, ON, \\ Canada
}

\begin{abstract}
Purpose: Older adults with chronic obstructive pulmonary disease (COPD) have a high risk and rate of falls. Home-based fall prevention exercise programs reduce falls in older adults and may be an alternative approach for people with COPD without access to hospital-based rehabilitation. Therefore, we aimed to determine the feasibility of a home-based fall prevention exercise program in older adults with COPD and to examine the effect of the program on fall-related outcomes at baseline, 3 and 6 months.
\end{abstract}

Patients and Methods: Adults $\geq 60$ years with COPD at risk for falls participated in a single group study. The intervention was a 6-month home-based fall prevention program which included 40 minutes of independent exercise three times per week, four physiotherapist home visits, bimonthly phone calls, and an optional booster session post-exacerbation. An independent assessor collected outcome measures at home at baseline, 3- and 6-months. Primary feasibility criteria were recruitment and retention rates $(\geq 70 \%)$ and exercise adherence $(\geq 60 \%)$. Functional outcomes included the Berg Balance Scale (BBS), the Balance Evaluation Systems Test (BESTest), the Activities-Specific Balance Confidence (ABC) scale, the repeated chair-stand test, self-reported function, and fall history.

Results: Thirty-six patients (female $63.8 \%$, mean age $74.4 \pm 6.1$ years; mean $\mathrm{FEV}_{1} 45.0 \pm$ $13.8 \%$ predicted) were enrolled. The recruitment rate was $46.8 \%$, participant retention rate was $69.4 \%$, and exercise adherence rate was $73.6 \%$. Repeated measures ANOVA showed improvements at 3- and 6-months compared to baseline in the BBS $(p=0.001)$ and the BESTest total scores and sub-scores $(p=0.001)$.

Conclusion: The home-based fall prevention exercise program met one of the three prespecified feasibility criteria (exercise adherence), and improved balance-related measures of fall risk in older adults with COPD. Our findings highlight important opportunities for refinement of the study design prior to undertaking a full-scale trial.

Keywords: COPD, balance training, exercise, falls prevention

\section{Introduction}

Chronic obstructive pulmonary disease (COPD) is a leading cause of disability and death worldwide. ${ }^{1}$ Impairments in muscle function, mobility, exercise capacity and more recently, balance, ${ }^{2,3}$ are well-recognized secondary effects of the disease. These impairments constitute fall risk factors ${ }^{4}$ and therefore likely contribute to the elevated fall risk in people with COPD. ${ }^{5-9}$ Participants with COPD are up to $55 \%$ more likely to fall than their age-matched peers. ${ }^{6}$ The higher potential for injury from a fall, frequent disease exacerbations, and unique impairment profile, underscore the need to develop fall prevention approaches specifically in COPD.

We have previously shown that a 6-week hospital-based balance training program provided alongside pulmonary rehabilitation improved measures of balance
Correspondence: Marla K Beauchamp McMaster University, School of Rehabilitation Science, 1400 Main Street West, Room 428, Hamilton, ON, L8S IC7, Canada

Email beaucm I@mcmaster.ca 
and disability in patients with COPD over the short-term. ${ }^{10}$ However, in order to impact on falls, exercises that target balance and functional strength need to be undertaken on a long-term basis. ${ }^{11}$ In addition, to be successful in COPD, barriers to program attendance and exercise adherence need to be addressed. Evidence supports home-based programs as one such strategy. ${ }^{12-15}$

The primary objective of this study was to determine the feasibility of home-based fall prevention exercise program for older adults with COPD in terms of recruitment, retention and adherence. Secondary feasibility outcomes included falls, patient satisfaction and adverse events. All feasibility outcomes will be used to inform a future largerscale trial. The secondary objective was to examine the effect of the program on fall-related outcomes including balance, functional strength and self-reported physical function. We hypothesized a priori that the home exercise intervention would be considered feasible if: 1) $\geq 70 \%$ of eligible participants could be recruited; 2) $\geq 70 \%$ of the sample completed all three study assessments; and 3) participants completed a minimum of $\geq 60 \%$ of the prescribed exercise sessions. We also hypothesized the program would have clinically important effects on intermediate outcomes linked to falls (balance, strength, function).

\section{Methods}

\section{Study Design}

This was a single-group, non-randomized clinical trial (clinical trials.gov NCT02695342). Eligible participants were enrolled in a 6-month home-based fall prevention exercise program. The home program was supervised by a physiotherapist and outcome measures were collected by an independent assessor at home at baseline, 3- and 6-months.

\section{Patient Involvement}

Participants with COPD were not involved in setting the research question, development of the study design or choice of outcome measures however they, along with clinicians working with patients with COPD, were consulted during the development of the home-based fall prevention exercise video. We intend to disseminate the main results to study participants and will seek patient involvement in refining the study design prior to a full-scale trial.

\section{Study Population}

Participants were recruited from respiratory medicine clinics at West Park Healthcare Centre (Toronto) and the
Firestone Institute for Respiratory Health (St. Joseph's Healthcare Hamilton) between 04/2016 and 02/2019 and were considered eligible if they met the following criteria: age $\geq 60$ years; a diagnosis of COPD; ${ }^{16}$ and a self-report of either 1) history of one or more falls in the previous year, 2) challenges with balance, or 3) worried about falling. ${ }^{17}$ Participants were excluded if they had completed a course of pulmonary rehabilitation (PR) in the previous 6 months or if they were on a wait list for admission to PR. Additional specific exclusion criteria included: residing outside of our pre-determined geographical catchment, inability to communicate due to language skills, hearing or cognitive impairment; history of unstable cardiovascular disease and marked resting or exertional oxygen desaturation, both of which would limit safe, independent exercise; evidence of a musculoskeletal or neurological co-morbidity which severely limited their mobility and/or jeopardized safety.

\section{Intervention}

The content and delivery of the home-based fallprevention exercise program was based on our work to date in COPD, ${ }^{10,18,19}$ best practice guidelines for fall prevention in older adults ${ }^{20}$ and evidence from successful home exercise interventions in older adults. ${ }^{15,21}$ Participants were instructed to perform 40 minutes of balance exercise at least three times per week for 6 months.

A registered physiotherapist (PT) taught the balance exercises in four home visits over the first 6 weeks of the study. The teaching sessions included a home safety assessment as well as instruction, demonstration, assessment of patient performance and prescription of appropriate balance exercises using based on patient needs. Participants also received a portable DVD player with a DVD version of the balance exercises as this strategy has shown promising results for facilitating home exercise adherence $e^{14,21,22}$ and patients were also provided with the option of an online link to the video (https://www.youtube. com/watch? $v=$ ShpqWhrfyBU\&feature $=e m b$ title). In general, the types of exercises were tailored to address the underlying balance deficits that we previously observed in this population ${ }^{23}$ and individualized according to each participant's ability. Specifically, the balance exercises emphasized functional lower extremity strength training (eg, sit to stand, step-ups, single-leg stance, seated hip abduction with an elastic band), gait training under challenging conditions (eg, heel and toe walking, backward 
stepping and figure $8 \mathrm{~s}$ exercise, exercises to challenge static balance control (eg, single-leg stance, narrow stance) and exercises to increase stability during changes in body positions (eg, sit to stand, stair taps). These are areas that we noted to be particularly deficient in patients with COPD in our previous work. The complete list of the exercises is available in Supplementary File 1.

The PT then placed bi-monthly telephone calls using scripted prompts (Supplementary File 1) to provide positive reinforcement and to assist patients with problemsolving any issues with the exercises or progression. In the event of a disease exacerbation, an additional booster session was offered to assist the participant in modifying and resuming the exercises.

\section{Primary Feasibility Measures}

1. Recruitment Data: (i) number of participants screened; (ii) proportion of participants ineligible and reasons; (iii) proportion of participants who declined to participate and reasons; (iv) number of participants enrolled. A recruitment rate of $\geq 70 \%$ of the eligible participant was considered feasible.

2. Retention Data: (i) proportion of participants with complete outcome assessments; (ii) number of withdrawals and reasons; and (iii) exercise adherence to the thrice weekly exercises prescription. The latter was collected using an exercise diary postcard (Supplementary File 1) and from standardized phone call questions. A retention rate of $\geq 70 \%$ of the sample was considered feasible.

3. Adherence rate: an overall exercise adherence rate of $\geq 60 \%$ was considered feasible. ${ }^{24}$

\section{Secondary Feasibility Measures}

To further inform the future design of a full-scale study we also collected data related to: 1) number of falls per participant; 2) adherence to monthly fall calendar return (Supplementary File 1); 3) patient satisfaction with the content and delivery aspects of the intervention using a standardized self-report questionnaire; 4) a list of adverse effects encountered (eg, musculoskeletal injuries); and 5) the number of sessions required with the PT for program modifications after exacerbations.

\section{Functional Outcomes}

- Falls: Fall history was measured at baseline and then prospectively using the monthly fall calendar return. The fall calendar postcards asked participants to indicate if they had a fall including a slip or trip in which they lost their balance and landed on the floor or ground or a lower level? ${ }^{25,26}$

- Balance: The 14-item Berg Balance Scale (BBS) was used as a measure of dynamic balance and the 36item Balance Evaluation Systems Test (BESTest) as a comprehensive measure of six balance control systems. Both tests evaluate performance of discrete physical tasks (eg, standing on one leg) based on specific time and performance criteria. Predictive validity for falls has been shown for the BBS in older adults ${ }^{27}$ and for the BESTest in neurologic populations, ${ }^{28}$ and there is strong evidence to support the construct validity, reliability and responsiveness of both balance scales in various older adult populations including COPD. ${ }^{27,29-31}$ Among those with COPD, a change of 5-7 points on the BBS and 13 points on the BESTest is clinically important. ${ }^{32}$

- Fear of falling: The Activities-Specific Balance Confidence $(\mathrm{ABC})$ scale requires patients to rate their confidence in maintaining their balance without becoming unsteady or falling during 16 progressively difficult activities such as standing on a chair and walking on an icy sidewalk. ${ }^{33}$ Total scores range from 0 to $100 \%$ with higher scores indicating greater confidence in remaining stable The ABC scale has good reliability and predicts falls in older adults residing in the community. ${ }^{27,33}$ In patients with COPD, the ABC scale has demonstrated construct validity as well as criterion validity for falls. ${ }^{29,34}$ A change of 19 points is considered clinically important in COPD. ${ }^{32}$

- Functional Strength: The repeated chair-stand test (number of sit-to-stands in 30 seconds) was used as a functional measure of lower body strength. The reliability and validity of this measure as a surrogate for strength has been demonstrated in older adults with COPD. ${ }^{35}$ A 3 repetition change is considered important. ${ }^{10}$

- Self-reported function: The physical function (PF-10) scale of the Medical Outcomes Study 36-Item ShortForm Health Survey was used to measure perceived limitations in overall physical functioning. Responses from each of the 10 items are scored on a 3-point Likert scale; scores range from 0 to 100 with higher scores indicating better function. The PF-10 has been widely used with good construct validity and sensitivity to change. ${ }^{36}$ A change of 10 points is clinically 
important in patients with COPD. ${ }^{37}$ Spirometry measures were conducted in line with the American Thoracic Society (ATS)/European Respiratory Society (ERS) criteria. ${ }^{38}$

\section{Descriptive Measures}

Measurements of height, weight, age, smoking history, medication use, number of co-morbidities, use of oxygen and/or a gait aid, pulmonary function and exercise capacity (6-minute walk distance: ${ }^{39}$ distance in meters that an individual is able to walk over a total of six minutes) were collected from the medical record and participant interview.

A global rating of change scale which asked participants to rate the amount of change they experienced in their balance was used upon completion of the intervention. The participant's perceived change in balance was rated on a five-point Likert scale (much better, a little better, no change, a little worse, or much worse).

\section{Statistical Analysis}

Clinical and demographic information were described using measures of central tendency and dispersion. Oneway repeated measures ANOVA were conducted to determine the effect of the home program on the participants' performance on the BESTest, BBS, ABC scale, repeated chair stand and self-reported function (PF-10 of the SF-36) measures at baseline compared to their performance at 3 and 6 months. Mauchly's test of sphericity indicated that the assumption of sphericity had been violated for the BESTest total score and subscale reactive. In those cases, the Greenhouse-Geisser correction was applied. In the case of a significant ANOVA, post hoc multiple comparisons with Bonferroni adjustment were conducted to determine the locus of the difference. Statistical analyses were performed using SPSS v. 26.0 and the statistical significance level was at $\alpha=0.05$.

A convenience sample of 36 subjects was recruited. This sample size was deemed sufficient to yield $80 \%$ power (alpha $=0.05$ ) to detect clinically important differences on the intermediate balance and functional measures pre- and post-intervention (20 required for the BBS and BESTest; $25-30$ for the ABC, chair-stand and PF-10) ${ }^{31}$ while accounting for a $15-20 \%$ drop-out rate based on our trial experience. ${ }^{10}$ The sample size was ${ }^{-}$determined using GPower software.

\section{Results}

Of the 265 participants screened for this study, 188 did not meet inclusion criteria, with the most common reason being that they lived too far from our geographic boundary $(\mathrm{n}=60)$ for home visits (Figure 1). Of the eligible patients, a total of 36 older adults with COPD consented to be enrolled in the study; 23 (63.8\%) females, mean age 74.4 \pm 6.1 years, and $\mathrm{FEV}_{1} \%$ predicted of $45.0 \%$ (13.8\%). On average, the participants were $10.8 \pm 7.7$ years from diagnosis of COPD with a smoking history of $45.7 \pm 13.4$ pack years. Fourteen participants (38.9\%) used supplemental oxygen and 14 used a gait aid. A fall history in the previous year was reported by 13 participants $(36.1 \%)$, $21(58.3 \%)$ self-reported balance problems and 18 (55.3\%) were worried about falling (Table 1).

\section{Primary Feasibility Findings}

Of the 77 participants who were eligible to participate in the study, 36 (46.8\%) consented to participate. Twenty-five enrolled participants $(69.4 \%)$ completed the three study assessments and exercise adherence rates were $83.4 \%$ at 3 -months and $73.6 \%$ at 6 -months.

\section{Secondary Feasibility Findings}

Eleven participants (30.6\%) suffered a total of 12 falls during the study period. Among 3-month completers and full program completers, the average monthly falls and exercise postcard return rate was $99 \%$ and $93 \%$ respectively. The average satisfaction rating was $4.6(0.46)$ on a 5-point Likert scale among program completers. Additionally, eight participants (32\%) perceived their balance as "much better", $13(52 \%)$ as "a little better" and four $(11.1 \%)$ as "unchanged". One serious adverse event related to study participation was reported; the participant tripped on the exercise stepper while performing the balance exercises and suffered an injurious fall (rib fracture, soft tissue injury to one shoulder). Thirteen participants reported a total of 22 acute exacerbations during the study period for an average of 0.61 acute exacerbations/participant; 5 participants required a fifth booster visit with a study PT to resume the home exercise program after an exacerbation.

\section{Effect of Home-Based Fall Prevention Exercise Training}

Data from 25 participants were compared between periods. Results of the one-way repeated measures ANOVA 


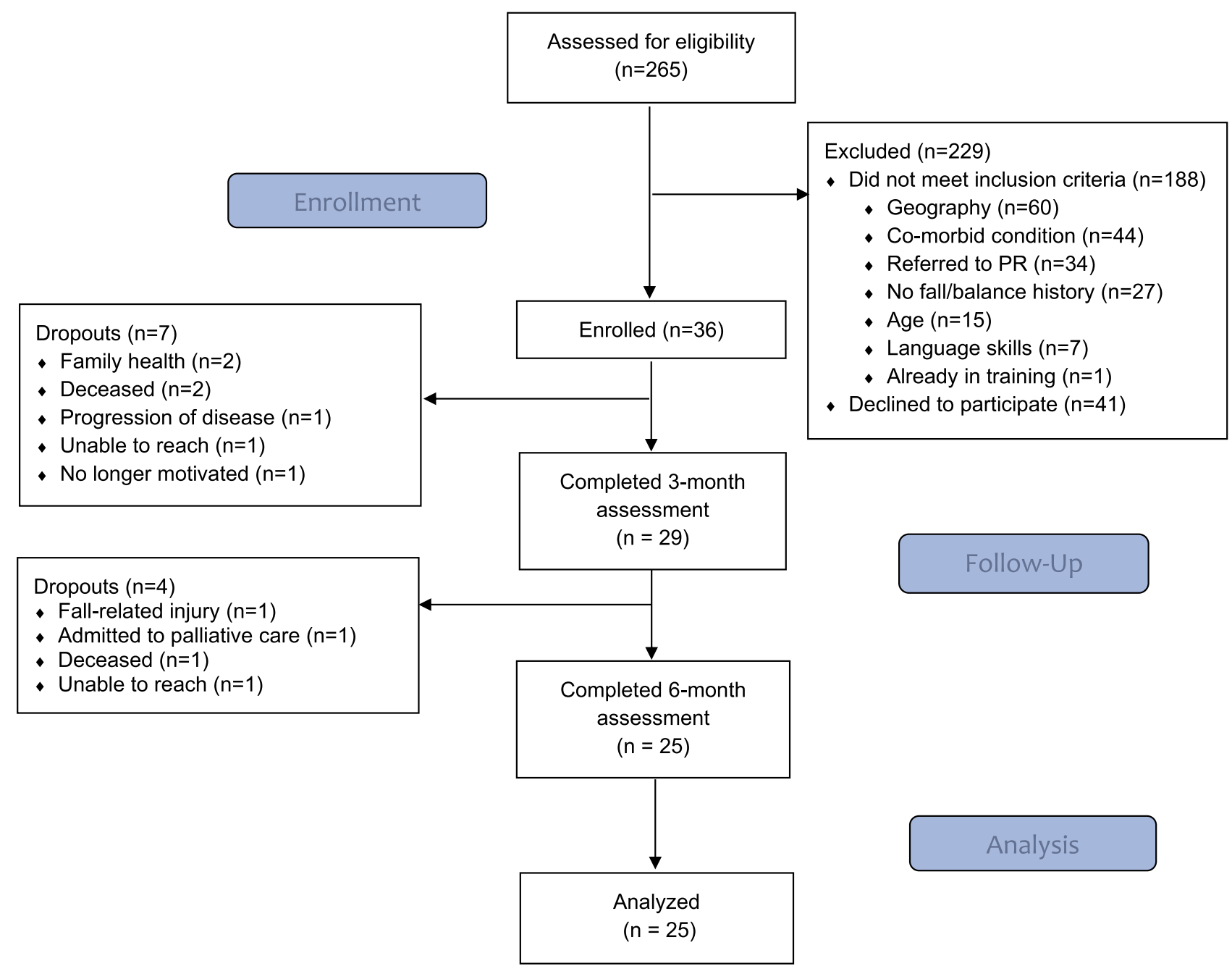

Figure I Consort flow diagram of the study.

showed that there was a significant main effect of the home balance exercise program on the BBS score $(p=$ 0.001). Adjusted Bonferroni post hoc tests showed that participant's performance on the BBS improved significantly from 49.3 (5.9) at baseline to 51.5 (4.7) at 3 months, and $51.8(5.0)$ at 6 months. BESTest total score also improved significantly $(\mathrm{p}=0.001)$ by an average of 7.7 at 3 months (65.5 vs 73.2) compared to baseline, and by 10.5 (65.5 vs 76.0) at 6 months compared to baseline. Similar results were found for the subsystems biomechanical constrains $(p=0.001)$, stability limits $(p=0.001)$, transitions $(p=0.001)$ and reactive $(p=0.004)$ with significant improvement at 3- and 6-months compared to baseline (Table 2). For the subsystem sensory orientation, significant differences were observed between measurements taken at baseline and at 6 months ( 74.4 vs 85.6 ), and at 3 and 6 months (77.6 vs 85.6). Figure 2 shows the comparison of the balance tests between time points. No differences between periods were observed for the subsystem of gait stability within the BESTest, the ABC scale, repeated chair stand, or PF-10 of the SF-36.

\section{Discussion}

To our knowledge this is the first study to examine a home-based fall prevention intervention for older adults with COPD. Our findings show that the home-based exercise program was feasible in terms of promoting long-term exercise adherence and was also associated with improvements in measures of balance related to fall risk over 6 months. We observed stagnation in most of the balance scores between 3 and 6 months. It is possible that clinically important improvements were already achieved or that further support would be needed by the physiotherapists in progressing the exercises further beyond 3 months. 
Table I Demographics and Clinical Characteristics of Enrolled Participants $(\mathrm{N}=36)$

\begin{tabular}{|c|c|}
\hline Variables & $\begin{array}{c}N=36 \\
\text { Mean } \pm S D\end{array}$ \\
\hline Age (years) & $74.4 \pm 6.1$ \\
\hline Sex, Feminine, N (\%) & $23(63.8 \%)$ \\
\hline BMI $\left(\mathrm{Kg} / \mathrm{m}^{2}\right)$ & $26.2 \pm 9.9$ \\
\hline Years since diagnosis & $10.8 \pm 7.7$ \\
\hline Smoking history, packs (years) & $45.7 \pm 13.4$ \\
\hline $\begin{array}{l}\text { Number of Comorbidities } \\
\text { Most common comorbidities, N (\%) }\end{array}$ & $4.6 \pm 2.3$ \\
\hline Hypertension & $21(58.3)$ \\
\hline Osteoarthritis & $18(50.0)$ \\
\hline Cardiovascular disease & $17(47.2)$ \\
\hline Depression & $13(36.1)$ \\
\hline Osteoporosis & II (30.6) \\
\hline Diabetes & $9(25.0)$ \\
\hline Number of Medications & $9.7 \pm 4.9$ \\
\hline $\begin{array}{l}\text { Most common treated conditions and medications } \\
\text { used, } \mathrm{N}(\%)\end{array}$ & \\
\hline Bronchospasm (bronchodilator) & $28(77.8)$ \\
\hline Hypertension (beta-blocker) & $16(44.4)$ \\
\hline Airway inflammation (corticosteroid) & $8(22.2)$ \\
\hline Diabetes (biguanide) & $7(19.4)$ \\
\hline $\begin{array}{l}\text { Depression (serotonin-norepinephrine reuptake } \\
\text { inhibitor) }\end{array}$ & $4(11.1)$ \\
\hline Anxiety (benzodiazepine) & $4(11.1)$ \\
\hline Pain (opioid) & $3(8.3)$ \\
\hline Number of exacerbations, $\mathrm{N}$ & 22 \\
\hline Number of patients hospitalized, $\mathrm{N}$ & 5 \\
\hline Falls history, N (\%) & \\
\hline No & $23(63.8)$ \\
\hline Yes & $13(36.2)$ \\
\hline Number of falls in the past 6 months, $\mathrm{N}$ & 16 \\
\hline Number of falls in the past 12 months, $\mathrm{N}$ & 28 \\
\hline Worry about falling, $N(\%)$ & \\
\hline No & $5(13.9)$ \\
\hline Yes & $21(58.3)$ \\
\hline Self-reported balance problems, $\mathrm{N}(\%)$ & \\
\hline No & $8(22.2)$ \\
\hline Yes & $18(55.6)$ \\
\hline Gait aids, N (\%) & \\
\hline Yes & $24(68.6)$ \\
\hline No & II (3I.4) \\
\hline Supplemental Oxygen, N (\%) & \\
\hline Yes & $14(38.9)$ \\
\hline No & $22(61.1)$ \\
\hline
\end{tabular}

(Continued)
Table I (Continued).

\begin{tabular}{|l|l|}
\hline Variables & \multicolumn{1}{|c|}{$\begin{array}{c}\text { N=36 } \\
\text { Mean } \pm \text { SD }\end{array}$} \\
\hline Lung Function & \\
FEV $_{\text {I }}(\mathrm{L})$ & $1.03 \pm 0.39$ \\
FEV $_{\text {I }} \%$ pred) & $45.03 \pm 13.80$ \\
FVC (L) & $2.17 \pm 0.59$ \\
FVC (\% pred) & $78.11 \pm 22.63$ \\
FEV $/$ FVC (\%) actual & $47.32 \pm 14.21$ \\
6MWD (m) & $319 \pm 109.2$ \\
\hline
\end{tabular}

Abbreviations: BMI, body mass index; FVC, forced vital capacity; $\mathrm{FEV}_{\mathrm{l}}$, forced expiratory volume in I second; 6MWD, six-minutes walk distance, $\mathrm{m}$, meters.

However, our retention rate was borderline acceptable (69.4\%), and our recruitment rate was lower than expected (47\%), though we did meet our required sample size. We also did not observe improvements in our secondary measures of functional strength and disability, and there was one adverse event related to the intervention. These findings highlight opportunities for refinement of the study design prior to undertaking a randomized controlled trial of home-based fall prevention in this population. We would recommend additional home visits by the PT to help maintain motivation and adherence in the latter half of the program; the addition of more exercises focused on total body functional strength; encouraging participants to have a family member or caregiver with them when exercising to limit the possibility of an adverse event such as a fall; and virtual sessions for those participants excluded due to geographic reasons. We also suggest strengthening screening for study inclusion, ie, for cognition and frailty, as both conditions could impact safe and effective participation in an independent program. Finally, we recommend the establishment of a patient stakeholder advisory group to partner with the research team to assist with refining recruitment and retention strategies, and to provide input on study design for a full-scale trial.

Our pre-specified feasibility outcomes for the trial were recruitment and retention rates of at least $70 \%$, and an exercise adherence rate of at least $60 \%$. Participants reported acceptable adherence to the prescribed three weekly 40minute exercise sessions at both 3- and 6-months (83 and $74 \%$ respectively), however only 25 out of the $36(69 \%)$ enrolled participants completed all three assessment sessions, falling just short of our pre-specified retention goal of $70 \%$. Although most participants dropped out of the study due to reasons unrelated to the intervention ( 3 deaths, 1 palliation, and 4 as a result of personal or family health issues), one 
Table 2 Comparisons of the Performance of the Participants on the Balance and Mobility Tests at Baseline, and at 3 and 6 Months $(n=25)$

\begin{tabular}{|l|c|c|c|c|c|c|c|}
\hline \multirow{2}{*}{ Variables } & Baseline & 3-Month & 6-Month & $\begin{array}{c}\text { Baseline vs } \\
\text { 3-Month }\end{array}$ & $\begin{array}{c}\text { Baseline vs } \\
\text { 6-Month }\end{array}$ & $\begin{array}{c}\text { 3-Month vs } \\
\text { 6-Month }\end{array}$ \\
\cline { 2 - 8 } & \multicolumn{3}{|c|}{ Mean (SD) } & \multicolumn{2}{|c|}{ P-value 95\% Cl of the Difference } \\
\hline BBS & $49.3(5.9)$ & $51.5(4.7)$ & $51.8(5.0)$ & $0.008 *-3.9--0.5$ & $0.021 *-4.6--0.3$ & $0.999-1.7-1.2$ \\
ABC & $65.6(24.1)$ & $70.1(18.4)$ & $72.6(16.0)$ & $0.455-12.3-3.3$ & $0.144-15.7-1.7$ & $0.999-9.3-4.2$ \\
Repeated Chair Stand & $7.9(3.2)$ & $9.1(3.2)$ & $8.4(4.2)$ & $0.063-2.5-0.1$ & $0.999-2.1-1.1$ & $0.700-0.8-2.3$ \\
SF-36 (PF-10) & $30.6(19.5)$ & $36.4(16.8)$ & $32.0(18.8)$ & $0.184-13.4-1.8$ & $0.999-12.3-9.5$ & $0.721-5.0-13.8$ \\
\hline BESTest & & & & & & \\
Biomechanical Constraints & $55.7(19.4)$ & $64.7(22.7)$ & $66.7(20.8)$ & $0.003 *-14.7--3.3$ & $0.001 *-16.1--5.8$ & $0.510-8.0--4.0$ \\
Stability Limits/Verticality & $69.3(10.3)$ & $77.5(9.9)$ & $80.6(9.4)$ & $0.001-12.2--4.2$ & $0.001-16.5--6.0$ & $0.378-8.0-1.9$ \\
Transitions/Anticipatory & $67.1(16.9)$ & $75.1(16.6)$ & $76.2(22.3)$ & $0.001 *-13.1--3.0$ & $0.002 *-13.9--3.0$ & $0.999-4.2-3.3$ \\
Reactive & $62.2(24.5)$ & $73.5(20.9)$ & $85.6(14.4)$ & $0.012 *-20.5--2.1$ & $0.023 *-26.4--1.6$ & $0.999-10.6-5.3$ \\
Sensory Orientation & $74.4(21.0)$ & $77.6(17.1)$ & $85.6(14.4)$ & $0.847-10.7-4.3$ & $0.010 *-20.0--2.4$ & $0.012 *-14.5--1.5$ \\
Stability in Gait & $64.0(18.9)$ & $68.8(17.0)$ & $71.6(19.8)$ & $0.077-9.9--0.4$ & $0.062-15.5-0.3$ & $0.716-8.9-3.2$ \\
Total Score & $65.5(12.6)$ & $73.2(11.9)$ & $76.0(12.3)$ & $0.001 *-10.9--4.5$ & $0.001 *-15.7--5.3$ & $0.094-6.0-0.3$ \\
\hline
\end{tabular}

Note: *Significant difference at $\mathrm{p}<0.05$

Abbreviations: BBS, Berg Balance Scale; BESTest, Balance Evaluation Systems Test; ABC, activities-specific balance confidence; PF-I0, physical function (PF-I0) scale of the Medical Outcomes Study; SF-36, 36-item short form health survey.

participant was lost to follow-up and another indicated they were no longer motivated to continue. It is possible that an additional visit by the treating physiotherapist may be necessary following the first 3 months of the program to help support patients in continuing the program over the longerterm. Of note, even though we had set an a priori recruitment rate of $70 \%$ as one of our feasibility criteria, we stopped recruitment once our target sample size was met, resulting in a rate of $47 \%$. Nonetheless, given that only $47 \%$ of eligible patients agreed to enroll in the program over 30 months, this suggests that multiple additional sites may be needed to meet sample size requirements for a larger trial. Our observed recruitment rate is also not surprising given that uptake for pulmonary rehabilitation is often low among people with $\mathrm{COPD}^{40}$ and that we targeted patients who were not enrolled or on a waitlist for rehabilitation. In our study, the primary reason participants offered for declining was related to either the time commitment or not feeling well enough to exercise; further exploration of the reasons why participants declined to participate would be helpful for informing future research. Many participants $(n=60)$ were also excluded given they resided outside of our pre-defined geographic catchment. Consideration of alternate delivery modes (eg, virtual) for the home-based exercise program may be worth considering in future studies.

Our secondary feasibility measures supported that the utilization of monthly postcards to collect exercise and falls data was effective. In addition, participants were highly satisfied with the program and $84 \%$ of program completers perceived some improvement in their balance. While monthly falls and exercise postcard return rates were high among 3-month (99\%) and program completers $(93 \%)$, there was some evidence of compliance fatigue in the 4- to 6-month period with the postcard return rate dropping to $86 \%$. Nonetheless, phone call follow-up for collecting the missing data was effective to gather the falls information in the event of missing postcards. A total of 11 participants $(30.6 \%)$ suffered a fall during the 6-month study period. It is difficult to interpret this finding without a control group, however the data may be useful for informing future sample size calculations. Five participants $(14 \%)$ required a booster visit to resume balance training after an acute exacerbation while eight participants $(22 \%)$ were able to resume the program without an additional visit from the PT. The relatively low percentage of participants requiring a booster visit supports the feasibility of this approach for selected patients who may require additional support.

Notably, one participant suffered a serious adverse event related to study participation resulting in an injurious fall. There are risks inherent in any exercise intervention involving vulnerable populations however balance training likely offers an additional safety challenge. To impact balance and fall risk, exercises must 

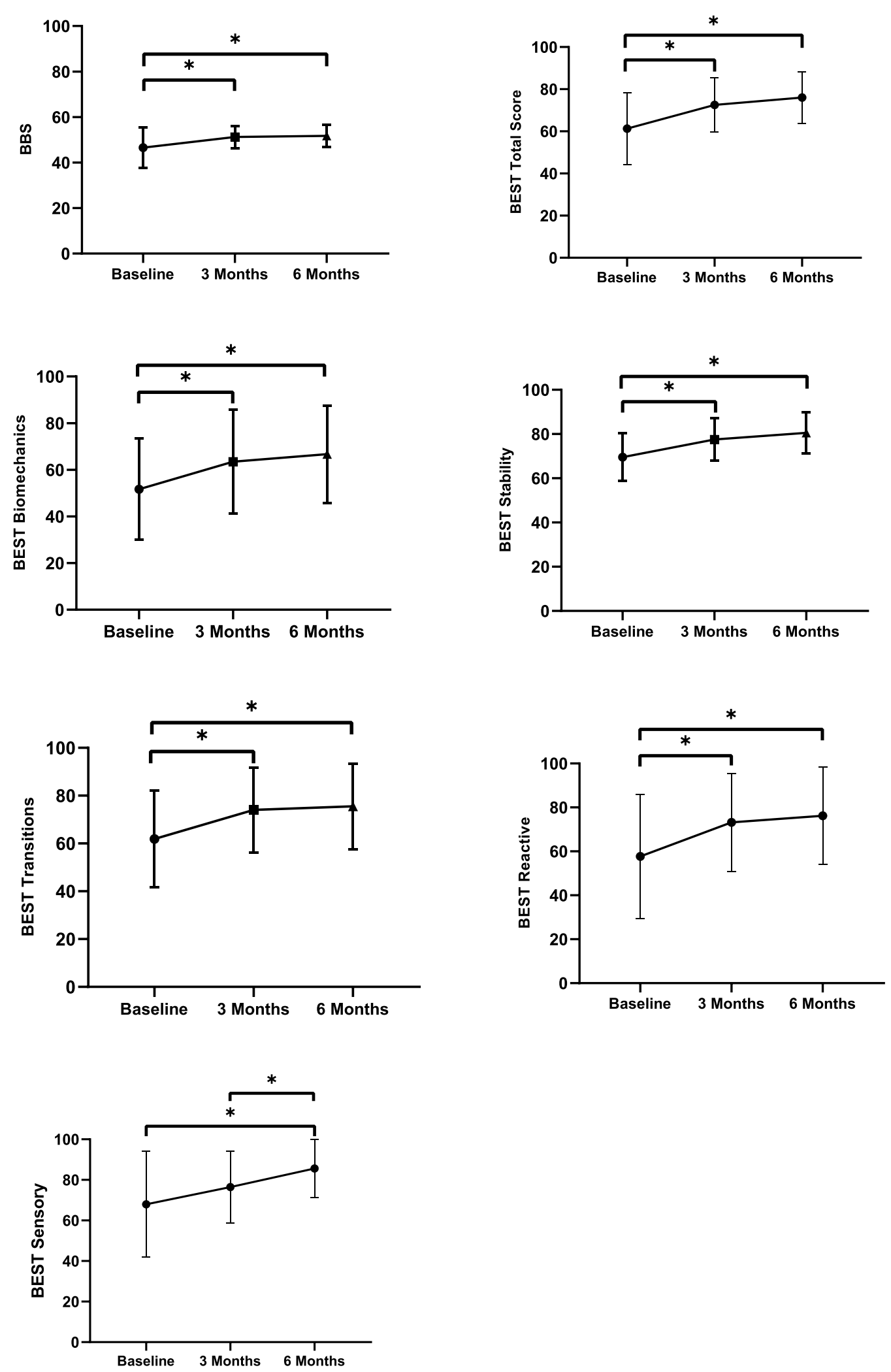

Figure 2 Repeated measures ANOVA determined that the balance tests differed significantly between time points. Post hoc tests using Bonferroni correction revealed that home balance exercise program improved the BBS score, the BESTest total score and the scores of the subcomponent's biomechanical constraints, stability, transitions, and reactive between baseline and 3 months and baseline and 6 months; and between baseline and 6 months, and 3 months and 6 months of exercise for the sensory subcomponent. $(*=p<0.05)$. 
take participants to the limit of their balance control thereby increasing the risk of falling during training by its very nature. Several steps were taken to mitigate this inherent risk. First, balance assessment results were used to tailor the home balance exercise program to each participant's abilities. This was essential in ensuring that participants were not under or over challenged. Second, a registered PT provided four 1:1 home-based training session during the first six weeks of the program. This allowed the PT to evaluate the participant's home environment for safety hazards, as well as ensure the participant was able to perform the exercises safely using items in the home such as a counter or table to offer standby support as needed. An additional strategy for future trials could be to encourage participants to have another family member nearby for safety if possible.

The home-based fall prevention exercise program was associated with statistically significant improvements in our primary balance measures- the BBS and BESTest. However, for the BBS, the improvement was below the MCID (5 points) for this measure established in our previous work. ${ }^{32}$ One reason for smaller improvement on the BBS may be the known ceiling effect for this measure- in fact, the baseline score on the BBS was 49.1 out of a total possible score of 56 . In contrast, scores on the more challenging BESTest improved by an average of 7.7 points at 3 months (65.5 vs 73.2) compared to baseline, and by 10.5 points ( 65.5 vs 76.0$)$ at 6 months compared to baseline. The improvement at 6-months compared to baseline meets the MCID for this assessment tool ${ }^{32}$ and suggests that the BESTest or one of its abbreviated versions would be optimal balance measure for future interventions. It is also encouraging to note the improvements in the six BESTest sub-scores. The non-significant improvements in our measure of fear of falling, functional strength and selfreported physical function are perhaps not surprising given that the exercise program was primarily designed to improve balance, and that small improvements in these measures could not have been detected with our sample size.

\section{Limitations}

This was a small-scale single-group, non-randomized clinical trial using a sample of convenience recruited from respirology clinics across two sites. As a result, the generalizability of our results to the broader COPD population is limited. The primary objective of this study, however, was to determine the feasibility of a home-based fall prevention exercise intervention as a novel way to address fall prevention in patients with COPD not enrolled in pulmonary rehabilitation.

Participant cognition and frailty were not formally assessed however they may play an important role in the safe and effective performance of the home-based fall prevention exercise program as well as have an impact on long-term adherence to the program. Results from this study will serve to inform a larger-scale study which can address some of the limitations noted here.

\section{Conclusion}

In summary, our study provides preliminary evidence to support the feasibility of a home-based fall prevention exercise program for older adults with COPD over 6 months. Additional strategies to improve the exercise program (eg, encouraging caregiver presence for safety), as well as to enhance recruitment and retention, are needed in advance of a larger trial. Data from the 3- and 6-month follow-up assessments show an encouraging improvement in balance-related measures of fall risk.

\section{Abbreviations}

COPD, chronic obstructive pulmonary disease; BBS, Berg Balance Scale; BESTest, Balance Evaluation Systems Test; PT, physiotherapist; PR, pulmonary rehabilitation, $\mathrm{ABC}$, activities-specific balance confidence; PF-10, physical function (PF-10) scale of the Medical Outcomes Study; SF-36, 36-item short form health survey; MCID, minimal clinically important difference, FVC, forced vital capacity; $\mathrm{FEV}_{1}$, forced expiratory volume in 1 second, $6 \mathrm{MWD}$, sixminute walk distance.

\section{Data Sharing Statement}

The dataset may be available from the corresponding author (Marla K Beauchamp) upon reasonable request.

\section{Ethics Statement}

This study was approved by the Hamilton Integrated Research Ethics Board (Project ID \#1072) and the Joint Bridgepoint/West Park/Toronto Central CCAC Research Ethics Board (Project ID \#15-027-WP); written consent was obtained from each participant. This study was conducted in accordance with the Declaration of Helsinki. 


\section{Acknowledgments}

The authors would like to thank Sachi O'Hoski and Annemarie Lee for their assistance in developing the home balance training DVD; Drs Joshua Wald and Natya Raghavan at St. Joseph's Healthcare Hamilton for their assistance with recruitment; Tamara Araujo at West Park Healthcare Centre for her assistance with recruitment, study management and data collection; Jocelyn Carr for providing the balance training sessions and the participants for the time they gave to the study.

\section{Author Contributions}

MKB conceived of the study and drafted the study protocol. $\mathrm{DB}, \mathrm{RG}, \mathrm{SP}$, and JR provided feedback on the study design and protocol. DH was responsible for recruitment and data collection. CE managed the study and assisted with data collection. RK conducted the data analysis and created the tables and figures. MKB and CE drafted the manuscript. All authors made a substantial contribution to the conception and design of the study, interpretation of the data, took part in revising and critically reviewing the article, agreed to submit to the current journal, gave approval for the final version and agree to be accountable for all aspects of the work.

\section{Funding}

This project was generously supported by the Labarge Optimal Aging Initiative Opportunities Fund. MKB is supported by an Emerging Research Leader Initiative from the Canadian Respiratory Research Network. DB is supported by a National Sanitarium Association Chair.

\section{Disclosure}

The authors report no conflict of interest in this work.

\section{References}

1. Wang H, Naghavi M, Allen C, et al. Global, regional, and national life expectancy, all-cause mortality, and cause-specific mortality for 249 causes of death, 1980-2015: a systematic analysis for the Global Burden of Disease Study 2015. Lancet. 2016;388(10053):1459-1544.

2. Loughran KJ, Atkinson G, Beauchamp MK, et al. Balance impairment in participants with COPD: a systematic review with meta-analysis. Thorax. 2020;75(7):539-546. doi:10.1136/thoraxjnl-2019-213608

3. Beauchamp MK. Balance assessment in people with COPD: an evidence-based guide. Chron Respir Dis. 2019;16:147997311 8820311. doi:10.1177/1479973118820311

4. Roig M, Eng JJ, Road JD, et al. Falls in patients with chronic obstructive pulmonary disease: a call for further research. Respir Med. 2009;103(9):1257-1269. doi:10.1016/j.rmed.2009.03.022

5. Roig M, Eng JJ, MacIntyre DL, et al. Falls in people with chronic obstructive pulmonary disease: an observational cohort study. Respir Med. 2011;105(3):461-469. doi:10.1016/j.rmed.2010.08.015
6. Hakamy A, Bolton CE, Gibson JE, et al. Risk of fall in patients with COPD. Thorax. 2018;73(11):1079-1080. doi:10.1136/thoraxjnl-20 17-211008

7. Sibley KM, Voth J, Munce SE, et al. Chronic disease and falls in community-dwelling Canadians over 65 years old: a population-based study exploring associations with number and pattern of chronic conditions. BMC Geriatr. 2014;14(1):22. doi:10.1186/ 1471-2318-14-22

8. Lawlor DA, Patel R, Ebrahim S. Association between falls in elderly women and chronic diseases and drug use: cross sectional study. BMJ. 2003;327(7417):712-717. doi:10.1136/bmj.327.7417.712

9. Oliveira CC, Lee AL, McGinley J, et al. Falls by participants with chronic obstructive pulmonary disease: a preliminary 12-month prospective cohort study. Respirology. 2015;20(7):1096-1101. doi:10.11 11/resp. 12600

10. Beauchamp MK, Janaudis-Ferreira T, Parreira V, et al. A randomized controlled trial of balance training during pulmonary rehabilitation for participants with COPD. Chest. 2013;144(6):1803-1810.

11. Sherrington C, Michaleff ZA, Fairhall N, et al. Exercise to prevent falls in older adults: an updated systematic review and meta-analysis. Br J Sports Med. 2017;51(24):1750-1758. doi:10.1136/bjsports-20 16-096547

12. Ashworth NL, Chad KE, Harrison EL, et al. Home versus center based physical activity programs in older adults. Cochrane Database Syst Rev. 2005;1:CD004017.

13. Strijbos JH, Postma DS, Van Altena R, et al. A comparison between an outpatient hospital-based pulmonary rehabilitation program and a home-care pulmonary rehabilitation program in patients with COPD. A follow-up of 18 months. Chest. 1996;109(2):366-372. doi:10.1378/chest.109.2.366

14. Moore J, Fiddler H, Seymour J, et al. Effect of a home exercise video programme in patients with chronic obstructive pulmonary disease. J Rehabil Med. 2009;41(3):195-200. doi:10.2340/16501977-0308

15. Campbell AJ, Robertson MC, Gardner MM, et al. Randomised controlled trial of a general practice programme of home based exercise to prevent falls in elderly women. BMJ. 1997;315(7115):1065-1069. doi:10.1136/bmj.315.7115.1065

16. Vestbo J, Hurd SS, Agusti AG, et al. Global strategy for the diagnosis, management, and prevention of chronic obstructive pulmonary disease: GOLD executive summary. Am J Respir Crit Care Med. 2007;176(6):532-555. doi:10.1164/rccm.200703-456SO

17. Stevens JA. The STEADI tool kit: a fall prevention resource for health care providers. IHS Prim Care Provid. 2013;39(9):162-166.

18. Beauchamp MK, Sibley KM, Lakhani B, et al. Impairments in systems underlying control of balance in COPD. Chest. 2012;141 (6):1496-1503. doi:10.1378/chest.11-1708

19. Harrison SL, Beauchamp MK, Sibley K, et al. Minimizing the evidence-practice gap - a prospective cohort study incorporating balance training into pulmonary rehabilitation for participants with chronic obstructive pulmonary disease. BMC Pulm Med. 2015;15 (1):73. doi:10.1186/s12890-015-0067-2

20. Rubenstein LZ, Kenny RA, Koval KJ, et al. Guideline for the prevention of falls in older persons. American Geriatrics Society, British Geriatrics Society, and American Academy of Orthopaedic Surgeons Panel on Falls Prevention. J Am Geriatr Soc. 2001;49(5):664-672.

21. Latham NK, Harris BA, Bean JF, et al. Effect of a home-based exercise program on functional recovery following rehabilitation after hip fracture: a randomized clinical trial. JAMA. 2014;311 (7):700-708. doi:10.1001/jama.2014.469

22. Stellefson M, Chaney BH, Chaney JD. Examining the efficacy of DVD technology compared to print-based material in COPD self-management education of rural patients. Calif J Health Promot. 2009;7(2):26-42. doi:10.32398/cjhp.v7i1.1318

23. Eisner MD, Blanc PD, Yelin EH, et al. COPD as a systemic disease: impact on physical functional limitations. Am J Med. 2008;121 (9):789-796. doi:10.1016/j.amjmed.2008.04.030 
24. Rivera-Torres S, Fahey TD, Rivera MA. Adherence to exercise program in older adults: informative report. Gerontol Geriatr Med. 2019;5:1-10. doi:10.1177/2333721418823604

25. The prevention of falls in later life. A report of the Kellogg International Work Group on the prevention of falls by the elderly. Dan Med Bull. 1987;34(Suppl 4):1-24.

26. Lamb SE, Jorstad-Stein EC, Hauer K, et al. Development of a common outcome data set for fall injury prevention trials: the prevention of falls network Europe consensus. J Am Geriatr Soc. 2005;53(9):1618-1622. doi:10.1111/j.1532-5415.2005.53455.x

27. Finch E. Physical Rehabilitation Outcome Measures: A Guide to Enhanced Clinical-Decision-Making. 2nd ed ed. Hamilton: Canadian Physiotherapy Association; 2002.

28. Duncan RP, Leddy AL, Cavanaugh JT, et al. Comparative utility of the BESTest, mini-BESTest, and brief-BESTest for predicting falls in participants with Parkinson disease: a cohort study. Phys Ther. 2013;93(4):542-550. doi:10.2522/ptj.20120302

29. Oliveira CC, Lee AM, Granger CL, et al. Postural control and fear of falling assessment in people with chronic obstructive pulmonary disease: a systematic review of instruments, international classification of functioning, disability and health linkage, and measurement properties. Arch Phys Med Rehabil. 2013;94(9):1784-1799 e7. doi:10.1016/j.apmr.2013.04.012

30. Beauchamp MK, O’Hoski S, Goldstein RS, et al. Effect of pulmonary rehabilitation on balance in persons with chronic obstructive pulmonary disease. Arch Phys Med Rehabil. 2010;91(9):1460-1465. doi:10.1016/j.apmr.2010.06.021

31. Horak FB, Wrisley DM, Frank J. The Balance Evaluation Systems Test (BESTest) to differentiate balance deficits. Phys Ther. 2009;89 (5):484-498. doi:10.2522/ptj.20080071

32. Beauchamp MK, Harrison SL, Goldstein RS, et al. Interpretability of change scores in measures of balance in people with COPD. Chest. 2016;149(3):696-703. doi:10.1378/chest.15-0717
33. Powell LE, Myers AM. The Activities-specific Balance Confidence (ABC) scale. J Gerontol a Biol Sci Med Sci. 1995;50A(1):M28-M34. doi:10.1093/gerona/50A.1.M28

34. Beauchamp MK, Hill K, Goldstein RS, et al. Impairments in balance discriminate fallers from non-fallers in COPD. Respir Med. 2009;103 (12):1885-1891. doi:10.1016/j.rmed.2009.06.008

35. Benton MJ, Alexander JL. Validation of functional fitness tests as surrogates for strength measurement in frail, older adults with chronic obstructive pulmonary disease. Am J Phys Med Rehabil. 2009;88 (7):579-83;quiz 84-6, 90. doi:10.1097/PHM.0b013e3181aa2ff8

36. Ware JE Jr, Kosinski M, Gandek B. SF-36 Health Survey: Manual and Interpretation Guide. Lincoln, RI: Quality Metric Inc; 2002.

37. Wyrwich KW, Fihn SD, Tierney WM, et al. Clinically important changes in health-related quality of life for patients with chronic obstructive pulmonary disease: an expert consensus panel report. $J$ Gen Intern Med. 2003;18(3):196-202. doi:10.1046/j.15251497.2003.20203.x

38. Rabe KF, Hurd S, Anzueto A, et al. Global strategy for the diagnosis, management, and prevention of chronic obstructive pulmonary disease: GOLD executive summary. Am J Respir Crit Care Med. 2007;176(6):532-555.

39. Casanova C, Cote CG, Marin JM, et al. The 6-min walking distance: long-term follow up in patients with COPD. Eur Respir J. 2007;29 (3):535-540. doi:10.1183/09031936.00071506

40. Hogg L, Garrod R, Thornton H, et al. Effectiveness, attendance, and completion of an integrated, system-wide pulmonary rehabilitation service for COPD: prospective observational study. COPD. 2012;9 (5):546-554. doi:10.3109/15412555.2012.707258

International Journal of Chronic Obstructive Pulmonary Disease

Dovepress

\section{Publish your work in this journal}

The International Journal of COPD is an international, peer-reviewed journal of therapeutics and pharmacology focusing on concise rapid reporting of clinical studies and reviews in COPD. Special focus is given to the pathophysiological processes underlying the disease, intervention programs, patient focused education, and self management protocols. This journal is indexed on PubMed Central, MedLine and CAS. The manuscript management system is completely online and includes a very quick and fair peer-review system, which is all easy to use. Visit http://www.dovepress.com/testimonials.php to read real quotes from published authors 